\title{
Translation of Research into Practice: Building Design
}

\author{
MARGARET LAW \\ Ove Arup Partnership, London
}

\section{ABSTRACT}

progress towards 'fire engineering by design' will be slow unless researchers can demonstrate to the public authorities and the engineering community that the objectives of fire precautions can be achieved more effectively than at present. Research can give methods of quantifying and defining the requirements for public safety. It is then possible for the building designer to adopt the fire protection measures appropriate to the use of the building and its importance in terms of people and property. Practical examples of applying fire engineering design methods are given.

\section{INTRODUCTION}

It is over ten years since I joined a large engineering practice, with the broad brief to "provide fire engineering by design". The results of fire research must be a major input, because most of our regulations and code of practice cannot be applied directly to innovative buildings. Working with creative architects and engineexs to find a practical solution is a challenge. The fire engineering advice must be soundly based and respect the needs and aspirations of the designers and users of the building. Fortunately the fire research is of a high standard, but the administrative procedures and bureaucratic attitudes we must work with can be frustrating. It is in changing these attitudes that I believe research should make a major impact. Except perhaps in North America, the relatively small numbers of professional fire engineers exert little influence at a national level; they are certainly not as influential as the structural engineers, for example. In this paper I would like to explore this theme but first, as the Erench say, a little history.

\section{THE LAST FOUR DECADES}

Forty years ago the UK government published a report on 'Fire Grading of Buildings'(1). The objectives of fire precautions were stated to be 'to safeguard life and property' and to this end fire precautions should aim 'to reduce the number of outbreaks of fire' and, in relation to fire grading, should 'Iimit the development and spread of a fire in the event of an outbreak and......provide for safe exit of occupants'. It was considered that a rational and economic combination of passive and active defence measures was the ideal, but was difficult to achieve in the absence of a coordinated body of fire statistics. 
Shortly after publication of the Report, the systematic collection of fire statistics was initiated. In 1980 the UK Home Office published a consultative document on 'Future Fire Policy' (2) which summarised the results of a study started in 1976 to review and measure the total cost of fire to the community and submit proposals as to the range and level of measures which should desirably be taken to have the optimum effect in mitigating losses. The fire statistics provided a major input. Some brief extracts from the report are given here.

The current numbers of annual deaths and injuries in the UK are 900 and 6000 respectively and the casualty problem which exists derives essentially from a number of small fires, mostly in dwellings, affecting just one person, normally close to the source of ignition'. In discussing Building Regulations and Iife safety the report suggests that because so high a proportion of fire casualties in dwellings results from personal incapacity or behavioural factors, there is Iittle scope for additions to the Regulations which could further influence life-safety. In the case of other occupied buildings, the number of casualties by type of building is too few to enable firm conclusions to be drawn'. The report draws attention to the high fire protection costs in large buildings to which the public are admitted and suggests they are expensive compared with those for other areas of public safety.

This report confirms that the UK fire grading requirements of the Regulations have been broadly successful in relation to life safety and structural stability. This is generally true for the other developed countries. Whether the requirements are rational and economic is a topic which is not really addressed in the report although there are some interesting assessments of the economic benefits to the community of installing active fire protection measures in various sectors.

\section{DEVELOPMENTS IN RESEARCH AND PRACTICE}

\section{Research and Regulations}

With the background of buildings being relatively successful in surviving fires, research has been devoted more to the behaviour of the contents. In relation to. life safety, the areas of research interest have been domestic dwellings and institutions. In relation to property safety, the major research interest has been in the contents of industrial and storage buildings. However, in practical building design the major constraints and the increased expenditure on fire safety, needed to comply with regulations, are incurred in quite different areas. For life safety, it is the buildings which contain large numbers of the public which are the major concern, while for property, the standards of protection, both active and passive, are being increased in buildings which are not particularly valuable, either in structure or in contents.

Why should this have happened? One reason is that the building authorities perceive - quite rightly in my view - that the larger the number of people exposed to risk, which means the more serious the consequences of failure, the higher the standard of public safety should be. However there is no agreed definition of this standard and no assessment of whether the measures required are effective and make the best use of resources. The fire authorities are only just beginning to admit that such an assessment is desirable but they believe it is not possible to do one. Research should show that it is possible and how it can be done. 
The authorities also perceive that the public can become alarmed by a large property loss, even when there axe no deaths or injuries. What is the critical size of loss and how does it vary with sector?

How much should public regulations mandate the safety of private property? Mandatory automatic sprinkler protection is increasing while at the same time the standards of structural fire protection, at least in the UK, are being raised.

The improvement in structural protection is being achieved not by changing the regulations, but by re-writing the rules for the design of elements to achieve a specified grade of fire resistance. Structural engineers protest that buildings designed to the old rules did not fall down in fires, so why is it necessary to increase the standard of protection? The grading should be reduced to maintain the status quo. The dilemma for the authorities is both political if the required levels of grading are reduced it will appear that safety is being decreased - and technical - what reduction can be accepted and does it apply to all structural matexials? If the beneficial effect of sprinklers can be recognised how is it quantified?

A further problem identified is the change in methods of structural design at normal temperatures: if there are smaller maxgins of safety in modern buildings, then past performance in fire cannot be relied on as a guide to their performance in the future. It is difficult to resolve these problems because although there have been many standard fire resistance tests carried out on single elements of construction, there has been much less study of the ways of assessing levels of safety or fire performance of building structures.

Research and Testing

Standard testing of materials and components is an important part of the procedure needed for compliance with the requirements of the authorities, but too many tests are administrative tools, not design tools. Tests become part of a regulation and are only incidentally fire safety measures. Any test method should at least define what is being measured and there should be an attempt to establish its relevance to practical conditions. The research people should be quite firm about this; if the authorities want a test they should say why it is wanted and what they hope to achieve. If they will not say this, then the research people should not be involved.

It is important that the authorities take into account the costs and benefits of the tests and regulations they impose. However, they should be clear about where their responsibilities end and the commercial market takes over. For example, our UK standard for fire resistance tests is currently undergoing extensive revision, in an attempt to obtain more uniform test results from the various commercial laboratories. The differences in results can be important in commercial terms to the manufacturers and the laboratories but if, as I suspect, they have little practical significance in relation to public safety then why involve the state-funded researchers and administrators? As far as I am aware, the authorities have not even asked the question - do these differences affect public safety? 


\section{Covered shopping Centres}

The covered shopping development, where the old style open street is replaced by a covered pedestrian mall, is familiar around the world. When they began to appear in the UK, the authorities perceived that they would break the rules on compartment size and therefore automatic sprinklers were required in all the shops, as an alternative method of reducing the chance of a fire becoming large. The safety of people escaping was then considered and it was realised that smoke protection of the malls would be needed so that there would be time for the people to reach the open air outside the development. The amount of smoke generated by a fire during the escape phase would determine the amount of smoke venting needed, but this was difficult to quantify. Instead, it was observed from statistics of sprinkler operation that most fires in shops were controlled by very few sprinkler heads, and it was decided that the final fire size was not likely to exceed a $3 \mathrm{~m} \times 3 \mathrm{~m}$ plan area. This size was therefore adopted for smoke design and assuming a heat output of about $0.5 \mathrm{MW} / \mathrm{m}^{2}$, a total size of $5 \mathrm{MW}$ was formulated. It is now part of the uk mythology. The Fire Research station produced design guidance for smoke venting the $9 \mathrm{~m}^{2}, 5 \mathrm{MW}$ fire, in a form which could be used by engineers; as a consequence, with new developments, the negotiations with the authorities are relatively straightforward.

As might be expected, the older shopping centres with open malls have become less popular and many are being refurbished and covexed. With the temperate climate of the UK, all that may be required is a fairly basic shelter from the wind and the rain and some simple measures to alleviate the effects of solar gain.

The first such scheme we became involved in was Basildon Town square. Here, shops border all four sides of a pedestrianized square which measures $200 \mathrm{~m}$ long by $36 \mathrm{~m}$ wide. A translucent fabric roof varying in height from $11.5-15 \mathrm{~m}$ was proposed, to cover the whole square. The enclosed space would not be conditioned, but would be naturally ventilated to be in balance with the exterior. With the square being enclosed the authorities immediately asked for sprinklers to be installed in all the shops. They were not concerned about an increased risk of fire spread but about smoke being contained and hampering escape from the square. Unfortunately the cost of the sprinkler systems and even more important, the costs of compensation for disruption of trading ruled out the sprinkler option.

The architects' view was that the enclosed space was so large that people could escape before smoke from a non-sprinklered fire became a problem. The national experts advised them however, that without sprinklers to control a fire it was not possible to establish the fire size as a basis for determining if the people would be safe. Not being convinced, the architects came to see me, and I suggested that we tried some scenarios, assuming a fire which was growing.

Most experimental studies of fire growth were of single artefacts burning in small rooms. These studies were the wrong scale for our problem. Fire statistics for actual fires in industrial buildings showed an exponential form of spread for fire-damaged area. There were no comparable data available for shops but we thought they were likely to be exponential too. Eventually, by using as a starting point the largest non-sprinklered shop permitted by regulations without smoke venting, we evolved a model which said that the fire area was initially $3 \mathrm{~m}^{2}$ and doubled in size every 4 minutes. (Recent analysis of statistics for shops indicates that 4 minutes is conservative). 
The convective heat output per unit fire area was taken as $0.5 \mathrm{MW} / \mathrm{m}^{2}$ as before and we assumed this all flowed into the square. The entrainment into the plume and the subsequent smoke layering under the roof were calculated using the Fire Research station methods, and we were able to estimate a time for the smoke to descend. This time had to be compared with the time taken for people to escape.

People needed time to move from a shop into the Square and then to walk across the square to an exit. Some of the distances were quite large compared with those in our codes. Our escape codes are based on travel distances and exit widths which will give evacuation within a notional $2 \frac{1}{2}$ minutes. A direct distance on plan to an exit from a shop is limited to $30 \mathrm{~m}$, and the fire authority will therefore quote a walking speed of $12 \mathrm{~m} / \mathrm{min}$. This speed actually relates to a crowa of people lining up in a corridor in order to move through an exit. In less crowded conditions people can move more quickly and can certainly cover a greater distance than $30 \mathrm{~m}$ in $2 \frac{1}{2}$ minutes. We allowed for this in assessing the time needed to evacuate the people in the square, and the people emerging from the surrounding shops. The fire authorities did not like this approach; they were, and are, very reluctant to accept increased travel distances, whatever the circumstances. In the end an extra exit was provided by sacrificing a shop unit. We did not think this extra exit was really needed but we were able to exploit it as a protected access point for the Fire Brigade.

Finally, we had to assess the effect of wind on the efficiency of the natural smoke venting. Mechanical extract was of course quite impractical because of the volumes involved. Wind tunnel tests were carried out to determine the location of the wind sensors and the sequence of operation of the vents.

Basildon Town Square was the first of many refurbishment projects we have worked on. Most of the shopping projects have been smaller than Basildon Town Square. Most of them are also without sprinklers, but for these we have not used the fire growth scenario. Instead, we have adopted an $18 \mathrm{~m}^{2}$ area $10 \mathrm{MW}$ fire for smoke venting design, on the assumption that a higher standard of smoke extract is needed where sprinklers are not installed. Statistics of fires in shops attended by fire brigades indicate that the chance that a fire in a sprinklered shop will exceed $9 \mathrm{~m}^{2}$ area is about the same as the chance that a fire in a non-sprinklered shop will exceed $18 \mathrm{~m}^{2}$. This comparison may not be directly relevant to the initial escape period of the fire but at least the risks appear comparable. On escape times we find that for a given population, in most circumstances the controlling factor is the width of the exits from the malls, rathex than the distance travelled to reach the exits. We also think that automatic detection systems and a public address system are important safety features, if early evacuation is to be achieved. The smoke extract may be mechanical but more often natural venting is used. Wind tunnel tests may be needed if there are adjacent tall buildings.

We use what research data we can to solve our problems; clearly, a great deal of research information is available for direct use, if only it can be presented in the right way. What is difficult to present is a sense of proportion. It seems wasteful to apply the same standards to all covered shopping centres whatever their size. Some single storey centres are smaller in area than one floor of a department store. Others are multi-storey and hold many people. Hand in hand with our fire and escape scenarios there should be some more explicit relationship between the level of safety and the number of people at risk. 
In the 19th century, the age of steam, large covered railway stations were built, with just enough vents in them to make them tolerable for the passengers. In the 20 th century we build large air terminals, without the steam and without the vents. These vast enclosures break the usual limits on compartment size in order to function efficiently. However, they are specifically designed to move people and we ought to be able to exploit this aspect for escape purposes. Our approach has been to categorise the public areas into two types of use. These are first, the concourse and waiting areas, with very low fire loads, which are places of relative safety and second the shop and catering areas with significant fire loads, which must be protected selectively. This we can do with automatic sprinklers and powered smoke extract designed to prevent smoke entering the concourse.

For terminals, as for shopping centres, we think the code limits on travel distance to an exit are not realistic. The assumption duxing normal working conditions in a terminal is that people move on average at about $1 \mathrm{~m} / \mathrm{s}$. Why should it be slower in fire conditions? We are obtaining measurements of the walking speed of people with baggage trolleys, as this is likely to be the critical value, and it does appear to be of the order of $1 \mathrm{~m} / \mathrm{s}$.

One terminal we are working on is a very large single-storey space, about $300 \mathrm{~m}$ long by $180 \mathrm{~m}$ wide by $12 \mathrm{~m}$ high. We would prefer people to escape directly to open air through exits on the perimeter, but this would mean their travelling longer distances than normal. The authorities want people to go down into a tunnel in order to limit the distance to an exit. We have therefore estimated the rate of smoke generation and movement in this large space and involved one of our environmental physicists to do the calculations using computer programs, in conjunction with the Fire Research station at Borehamwood. In large buildings such as this and in large atrium buildings a fire can be considered initially as a local injection of hot air into the building environment. The effect of building physics becomes an important aspect of fire safety design.

\section{Atriums}

We have followed the fashion from the USA, and atriums are now very popular architectural features. For fire safety reasons, our authorities have ensured that many atriums are rather sterile spaces, with not much more fire load than a few plants, and they are mainly confined to office bujldings. There is much confusion about the fire safety measures which should be adopted. For acoustic reasons thexe is usually glazing between the atrium and the surrounding accommodation. Drenchers may be required on the glazing as well as arbitrary smoke venting provisions. Some people have adopted the mythical 5 MW fire as a basis for smoke design although there is no obvious reason why offices and covered shopping centres should be treated in the same way. There is no explicit recognition that the rules should take into account the number of people at risk and the nature of the risk. The rules that we may well be saddled with are likely to be dominated once again by the needs of the bureaucrats to pass or fail a building, and not by the need to design fire safety for buildings that people want. We need the intellectual rigour of the researcher to question such rules and provide an alternative rational framework. 
The use of the fire resistance test for the grading of structures is not often questioned by engineers, although it is perceived as irrational. They would like an alternative 'compartment fire', approach to be available for those occasions where it can be demonstrated that because of the nature and disposition of the building contents the fire exposure is different from that normally assumed. The detailing of structural assemblies is perceived as an important area which has not been studied sufficiently while the development and acceptance of calculation methods for fire resistance proceeds rather too slowly.

\section{WHAT THE DESIGNER NEEDS}

For many simple, run-of-the-mill buildings, the architect and engineer will prefer to have simple, if arbitrary, rules. For more complex buildings, the designers need to have flexibility if they are to provide a cost-effective building which meets the needs of the client and the people who use the building.

There are many constraints on the design of a building; fire safety is one important, but small aspect which cannot be allowed to dominate. What is needed is a choice of measures which in combination can achieve a required level of safety. Physical limitations may preclude the use of an extra escape route, or an element of a given fire resistance rating. What compensatory measures could be acceptable? We need a rational framework and agreed numbers.

I believe that we have enough information available to produce the rational framework. If we are successful then the practitioners and administrators will start to ask the right questions - which will benefit us all.

\section{REFERENCES}

1. Fire Grading of Buildings. Part 1. Post-war Building Studies No. 20. The Ministry of Works, London, H M Stationery Office, 1946.

2. Future Fire Policy. A Consultative Document. Home office Scottish Home and Health Department, London, H M Stationery office, 1980. 
